Original Article

\title{
TOXIC AND IMMUNOTOXIC EVALUATION OF KETAMINE AND/OR ETHANOL IN RATS DURING 28 DAYS
}

\author{
PATRICIA FRANCISCONE MENDES ${ }^{1}$, KARIN ARGENTI SIMON², ISIS MACHADO HUEZA ${ }^{1,2 *}$
}

${ }^{1}$ Department of Pathology, School of Veterinary Medicine and Animal Science, University of Sao Paulo, Sao Paulo, S. P., Brazil, ${ }^{2}$ Institute of Environmental, Chemical and Pharmaceutical Sciences, Federal University of São Paulo (ICAQF-UNIFESP), Diadema, S. P., Brazil Email: imhueza@unifesp.br

Received: 08 Jun 2017 Revised and Accepted: 22 Jul 2017

\section{ABSTRACT}

Objective: Studies have shown that ketamine (K) and ethanol (E) have immunomodulatory activity; however, few studies were performed with concomitant treatments. Thus, we evaluated the toxic and immunotoxic effects of this association.

Methods: Wistar rats were distributed into four groups (n=8/group), each receiving one of the following treatments, for $28 \mathrm{~d}: \mathrm{K}$ group (15 mg/kg of ketamine, intraperitoneally); E group [1.0 ml of ethanol 10\% (approximately 0,08g/rat), gavage]; KE group, receiving both treatments; and Control (Co) group, receiving only vehicles. On day 29, animals were euthanized for biochemical, hematological, histopathological and immunological evaluation.

Results: Although the experimental conditions did not elicit changes on immune parameters, some biochemical alterations were detected in the different groups. Even in the absence of nutritional and histopathological changes, or renal and hepatic markers that could indicate tissue damage, a reduction on alkaline phosphatase levels in rats from $\mathrm{K}$ and $\mathrm{KE}$ groups was observed. Moreover, changes in lipid markers [cholesterol, triglycerides and high-density lipoproteins (HDL)] were found in the different groups studied, suggesting that $\mathrm{K}$ and $\mathrm{E}$ could promote a synergic/antagonistic effect.

Conclusion: In conclusion, despite biochemical alterations promoted by $\mathrm{K}$ and $\mathrm{E}$, associated or not, the doses here employed did not promote immunotoxic effects on rats treated for $28 \mathrm{~d}$. (response to the suggestion in the end of the paper).

Keywords: Special K, K-hole, Immunotoxicity, Ketamine, Alcohol

(C) 2017 The Authors. Published by Innovare Academic Sciences Pvt Ltd. This is an open access article under the CC BY license (http://creativecommons.org/licenses/by/4.0/] DOI: http://dx.doi.org/10.22159/ijpps.2017v9i9.20582

\section{INTRODUCTION}

The use of substances with psychoactive properties is considered an ancient and universal practice [1], associated either with cultural or religious rituals, as well as for medicinal purposes. In the $19^{\text {th }}$ century, medical sciences advancements, resulting in the discovery of new drugs and routes of administration [2, 3], collaborated to change the purposes of the use of these substances for its current consumption, focused on the recreational use and individual pleasure [4]. Later in the $20^{\text {th }}$ century, when abuse and dependence epidemics began [5], causing social problems of public health concern, investigations involving the increase on the prevalence of illicit drugs use gained more prominence and importance $[6,7]$.

In the present scenario, a growing number of new psychoactive substances has been reported [8] and the common occurrence of the concomitant use of these different chemicals resulted in the concept of "polydrug" abuse [9], with ethanol as the most prevalent substance used in association with stimulants and/or hallucinogenic drugs, such as ketamine [10]

The total quantity of ketamine seized worldwide mostly originated from East and South-East Asia to Europe and America [11, 12], increased from an annual average of 3 tons in the period of 19982008 to 10 tons in the period of 2009-2014 [13]

Some harmful adverse physical (hypertension, tachycardia, abdominal and urinary pain syndrome) and neurological (disorientation, agitation, hallucinations, anxiety and psychosis) effects, after prolonged use or high doses of ketamine, framed it as a "Class B Drug", controlled by the United Kingdom Misuse of Drugs Act 1971 since 2014 [14] and added to "Schedule III" in the United States since 1999 [15].

Ketamine is a phencyclidine analog drug which acts mainly as an antagonist of N-methyl D-aspartate (NMDA) glutamate receptors [16]. It is used in human medicine as a short-term anesthetic for specific situations (palliative care, pediatric and emergency surgeries) and, currently, as an alternative treatment for depression in patients unresponsive to conventional treatments $[17,18]$. However, due to the unpleasant central effects caused to human patients under anesthesia, such as anxiety, agitation and hallucinations [19, 20], it is most commonly used in veterinary practice [21].

Studies with ketamine revealed its immunomodulatory properties [22], characterized by suppressed production of cytokines tumor necrosis factor-alpha (TNF- $\alpha$ ) and interleukin-6 (IL-6) $[23,24]$, limiting neutrophil diapedesis to inflammation sites [25, 26], even though interleukin-2 (IL-2) secretion and cellular adhesion molecules expression are maintained $[23,24]$.

Ethanol, the most common and popular licit drug, widely used in association with other drugs $[27,28]$, is a central nervous system (CNS) depressant that potentiates the gamma-amino butyric acid (GABA) effects, acting in agonist form on GABAergic receptors [29], culminating in delayed conduction of nerve impulses and, consequently, muscle relaxation and sleepiness [30]. In addition to central symptoms, ethanol exposure can trigger immunosuppressive effects on monocyte, macrophage and neutrophil activities [31].

Considering that there are few reports in the literature about the possible toxic, and/or immunotoxic effects resulting from ketamine/ ethanol association, the present study aimed to evaluate the effects of combined daily intraperitoneal injections of ketamine and oral (gavage) administration of ethanol to Wistar rats, for a period of $28 \mathrm{~d}$.

\section{MATERIALS AND METHODS}

Material

Animals

Thirty-two male adult Wistar rats (60 d of age, $200-250 \mathrm{~g}$ body weight) were obtained from our colony in the Department of Pathology, School of Veterinary Medicine and Animal Science, 
University of São Paulo. The animals were used in accordance to the ethical principles and procedures adopted by The Ethics Committee on Animal Experiments of the School of Veterinary Medicine, University of São Paulo, Brazil (protocol number: 8108060616). All rats were housed in cages measuring $40 \times 50 \times 20 \mathrm{~cm}$. Two rats were placed in each cage, with a dividing grid that allowed the animals visual and some physical contact, without interfering with individual feed and water consumption, thus reducing the stress resulting from isolation. The cage bottoms were lined with sterilized corncob. Cages were checked daily over the entire experimental period for soft feces, food waste, behavioral changes (e. g., piloerection, lethargy) and mortality. The animals received food and water ad libitum and were maintained under controlled temperature $\left(22-25^{\circ} \mathrm{C}\right)$, relative humidity (50-65\%) and lighting (12/12h light/dark cycle).

\section{Drugs, chemicals and reagents kits}

Phormol 10\% was supplied by Merck (São Paulo, SP, Brazil). Sodium heparin was obtained from Cristália (São Paulo, SP, Brazil). Archote (Curitiba, PR, Brazil) supplied ethanol. Roswell Park Memorial Institute culture medium (RPMI-1640), fetal bovine serum (FBS), and trypan blue were obtained from Gibco (United States of America, USA). Synth (Diadema, SP, Brazil) provided sodium chloride. Davol (São Paulo, SP, Brazil) supplied assay reagents for hematological parameters [red blood cells/erythrocytes (RBC), white blood cells/leukocytes (WBC), hemoglobin (HGB), hematocrit (HCT), platelets (PLT), mean corpuscular volume (MCV), mean corpuscular hemoglobin $(\mathrm{MCH})$, and mean corpuscular hemoglobin concentration (MCHC)]. Interteck (São Paulo, SP, Brazil) supplied assay kits for albumin, total protein, alkaline phosphatase (ALP), alanine transaminase (ALT), aspartate transaminase (AST), gamma-glutamyl transpeptidase (GGT), glucose, cholesterol, triglycerides, and high-density lipoproteins (HDL), urea, and creatinine. Ceva (Paulinia, São Paulo, Brazil) provided Ketamin (Dopalen ${ }^{\circledR}$-ketamine hydrochloride $1.16 \mathrm{~g}$; vehicle q. s. $10.0 \mathrm{ml}$ ) and Xylazine (Anasedan ${ }^{{ }_{-}}$ xylazine hydrochloride $2.3 \mathrm{~g}$; vehicle q. $\mathrm{s}$. $100.0 \mathrm{ml}$ ). All other reagents were supplied by Sigma-Aldrich (Saint Louis, Missouri, USA).

\section{Methods}

\section{Toxicological and immunotoxicological evaluations}

Thirty-two male Wistar rats were randomly distributed into four groups ( $\mathrm{n}=8$ animals/group), consisting of one control group (Co) and three experimental groups (ketamine [K], ethanol [E] and ketamine+ethanol [KE]). Rats from K group were treated once, daily, with an intraperitoneal (I. P) injection of $15 \mathrm{mg} / \mathrm{kg}$ of ketamine [based on the dose published by Garcia et al., Rezin et al., and Réus et al. (32-34)] diluted in saline solution $0.9 \%$, and orally by gavage with $1.0 \mathrm{ml}$ of distilled water for each rat. Rats from E group were treated once, daily, by gavage with $1.0 \mathrm{ml}$ of ethanol $10 \%$ [approximately $(\approx) 0,08 \mathrm{~g} / \mathrm{rat}$ ] [calculated dose based on studies of Wai et al. (35)], and with an I. P injection of $1.0 \mathrm{ml}$ of saline solution $0.9 \%$ for each rat. Rats from KE group were treated once, daily, with an I. P injection of $15 \mathrm{mg} / \mathrm{kg}$ of ketamine diluted in saline solution $0.9 \%$, and by gavage with $1.0 \mathrm{ml}$ of ethanol $10 \%(\approx 0,08 \mathrm{~g} / \mathrm{rat})$. Rats from Co group were treated once, daily, with an I. P injection of 1.0 $\mathrm{ml}$ of saline solution $0.9 \%$ for each rat, and by gavage with $1.0 \mathrm{ml}$ of distilled water for each rat, only to be subjected to similar stimuli to those applied to the animals belonging to the experimental groups. All rats were treated between 8:00 a. m. and 12:00 p. m., and all treatments were done simultaneously. Food and water consumption, as well as body weight gain, were assessed daily to determine total weight gain, as well as total water and food consumption. Rats were treated for 28 consecutive days according to immunotoxicological protocols employed worldwide. On the $28^{\text {th }}$ day, food was removed and the rats were fasted for $8 \mathrm{~h}$ for biochemical evaluation.
After the last day of the experimental period, the animals were anaesthetized with xylazine and ketamine $(5$ and $50 \mathrm{mg} / \mathrm{kg}$ of body weight, respectively) for blood collection from the abdominal cava vein. Euthanasia of deeply anesthetized animals was made by cervical dislocation, in accordance to The Ethics Committee on Animal Experiments of the School of Veterinary Medicine, University of São Paulo, Brazil. Lymphoid organs (thymus and spleen) and bone marrow from the left femur were removed for lymphohematopoietic organ and cellularity analysis.

Blood collection was performed with and without sodium heparin for the evaluation of hematological parameters and serum biochemical analyses, respectively. Hematological parameters (RBC, WBC, HGB, HCT, PLT, MCV, MCH, and MCHC) were assessed using automatic Poch-100iV Diff Sysmex ${ }^{\circledR}$ equipment; differential white blood cells analyses (neutrophils, lymphocytes, monocytes, eosinophils, and basophils) were performed manually (blood extension). Serum biochemistry was analyzed using ChemWell ${ }^{\circledR}$-T automated biochemistry analyzer with the corresponding reagents. The measured markers were albumin, total protein, ALP, ALT, AST, GGT, glucose, cholesterol, triglycerides, HDL, urea, and creatinine.

For urinalysis, after bladder exposure, approximately $1.0 \mathrm{ml}$ of urine was collected by puncture of the organ and placed into tubes containing urinalysis reagent strips from Labtest (Uriquest ${ }^{\circledR}$ ) for semi-quantitative determination of $\mathrm{pH}$, density, and presence of bilirubin, urobilinogen, ketones, ascorbic acid, glucose, protein, blood, nitrite, and leukocytes in the urine.

Tissue samples of heart, liver, Peyer's patches, mesenteric lymph nodes, adrenal glands, kidney, and bladder were collected and fixed in $10 \%$ formalin, routinely embedded in paraffin, cut into $5-\mu \mathrm{m}$ thick sections and stained with hematoxylin and eosin for histopathology. After relative organ weight analysis of thymus and spleen, these organs were fixed in formaldehyde for histopathology evaluation.

A fragment of a known weight of splenic tissue was prepared, washed in cold RPMI-1640 culture medium, and resuspended in 5 $\mathrm{ml}$ of the culture medium for splenocytes count; the remaining fragment was fixed for histopathology analysis. Bone marrow cell suspensions were produced by flushing the marrow cavity of the left femur of each rat with an ice-cold RPMI-1640 medium using a sterile syringe with a 26 -gauge needle.

The viability of white blood cells from spleen and bone marrow was assessed by a trypan blue dye exclusion test, and cell number was determined by Neubauer Chamber cell counting.

\section{Statistical analysis}

Data were analyzed using GraphPad Prism 6.0 ${ }^{\circledR}$ software (GraphPad Software, Inc., San Diego, California). One-way analysis of variance (ANOVA) followed by Tukey's test was used for multiple comparisons. If Bartlett's test suggested that the differences among SEM values were significant, Kruskal-Wallis analysis of variance followed by Dunn test for multiple comparisons was employed. Data are expressed as mean \pm standard error of the mean (SEM), and differences were considered to be statistically significant when ${ }^{*} \mathrm{P}<0.05$.

\section{RESULTS}

Food and water consumption, body weight gain and toxicity signs

During the experimental period, none of the rats showed signs of toxicity, such as soft feces, depression, piloerection, or mortality. Table 1 shows total food and water consumption, and total body weight gain of rats treated or not (Control) with ketamine (K), ethanol (E) or both ketamine and ethanol (KE) during $28 \mathrm{~d}$.

Table 1: Total food and water consumption, and total body weight gain of rats treated or not (Control) with ketamine (K), ethanol (E) or ketamine+ethanol (KE) during $28 \mathrm{~d}$

\begin{tabular}{llll}
\hline & Control (n=8) & K (n=8) & E (n=8) \\
\hline Food consumption $(\mathrm{g})$ & $669.9 \pm 16.0$ & $698.1 \pm 14.2$ & $685.5 \pm 15.6$ \\
Water consumption (ml) & $938.4 \pm 24.8$ & $923.9 \pm 37.7$ & $872.5 \pm 31.6$ \\
Body weight gain $(\mathrm{g})$ & $109.3 \pm 12.0$ & $109.6 \pm 10.4$ & $109.0 \pm 11.4$ \\
\hline
\end{tabular}

Data are presented as mean \pm SEM. 
Hematological parameters and lymphoid organ evaluation (relative weight of spleen and thymus, and bone marrow and spleen cellularity)

The statistical tests employed to evaluate hematological parameters and blood counts did not reveal any significant differences among the groups and parameters evaluated (data not shown). In relation to lymphoid organ evaluation (relative weight of spleen and thymus, and bone marrow and spleen cellularity), no significant differences were found among the experimental groups, as indicated in table 2 .

\section{Urinalysis}

No significant differences were found in urine parameters $\mathrm{pH}_{\text {, }}$ density, bilirubin, urobilinogen, ketones, ascorbic acid, glucose, protein, blood, nitrite, and leukocytes) among the groups after the 28-day experimental period (data not shown).

\section{Biochemical parameters}

No alteration was observed in total protein, albumin and glucose serum levels. Despite the lack of changes in hepatic parameters ALT (fig. 1A), AST (fig. 1B), and GGT (fig. 1C), a reduction in ALP levels was observed in rats treated with $\mathrm{K}$ compared with those treated with either E or vehicle (Co group); in addition, ALP was also reduced in rats treated with $\mathrm{KE}$ when compared with rats from Co group (fig. 1D).

When lipid profile was assessed, we observed higher cholesterol levels in the rats from KE group when compared with rats from Co group (fig. 2A). However, when triglycerides levels were evaluated, animals from $\mathrm{K}$ group revealed statistical reduction on this parameter when compared with both Co and KE group, with no statistical differences from animals of E group, as shown in fig. 2B. In addition, rats from all groups showed enhanced levels of HDL compared with rats from Co group (fig. 2C).

Table 2: Relative weight of spleen and thymus, and bone marrow and spleen cellularity of rats treated or not (Control) with ketamine (K), ethanol (E) or ketamine+ethanol (KE) during $28 \mathrm{~d}$

\begin{tabular}{llll}
\hline & Control (n=8) & K (n=8) & E (n=8) \\
\hline Spleen $\left(\mathrm{x} 10^{-3} \mathrm{~g} / 100 \mathrm{~g}\right.$ of BW $\left.\mathrm{a}\right)$ & $0.27 \pm 0.01$ & $0.25 \pm 0.01$ & $0.26 \pm 0.01$ \\
Thymus $\left(\mathrm{x} 10^{-3} \mathrm{~g} / 100 \mathrm{~g}\right.$ of BW $\left.{ }^{\mathrm{a}}\right)$ & $0.14 \pm 0.01$ & $0.16 \pm 0.01$ & $0.26 \pm 0.01$ \\
Spleen cellularity $\left(\mathrm{x} 10^{6} / \mathrm{g}\right.$ of spleen) & $210.7 \pm 12.4$ & $225.4 \pm 24.2$ & $0.14 \pm 0.01$ \\
Bone marrow cellularity (x106ells) & $5.09 \pm 0.7$ & $5.70 \pm 1.0$ & $201.0 \pm 15.5$ \\
\hline
\end{tabular}

aBW = Body weight. Data are presented as mean \pm SEM.

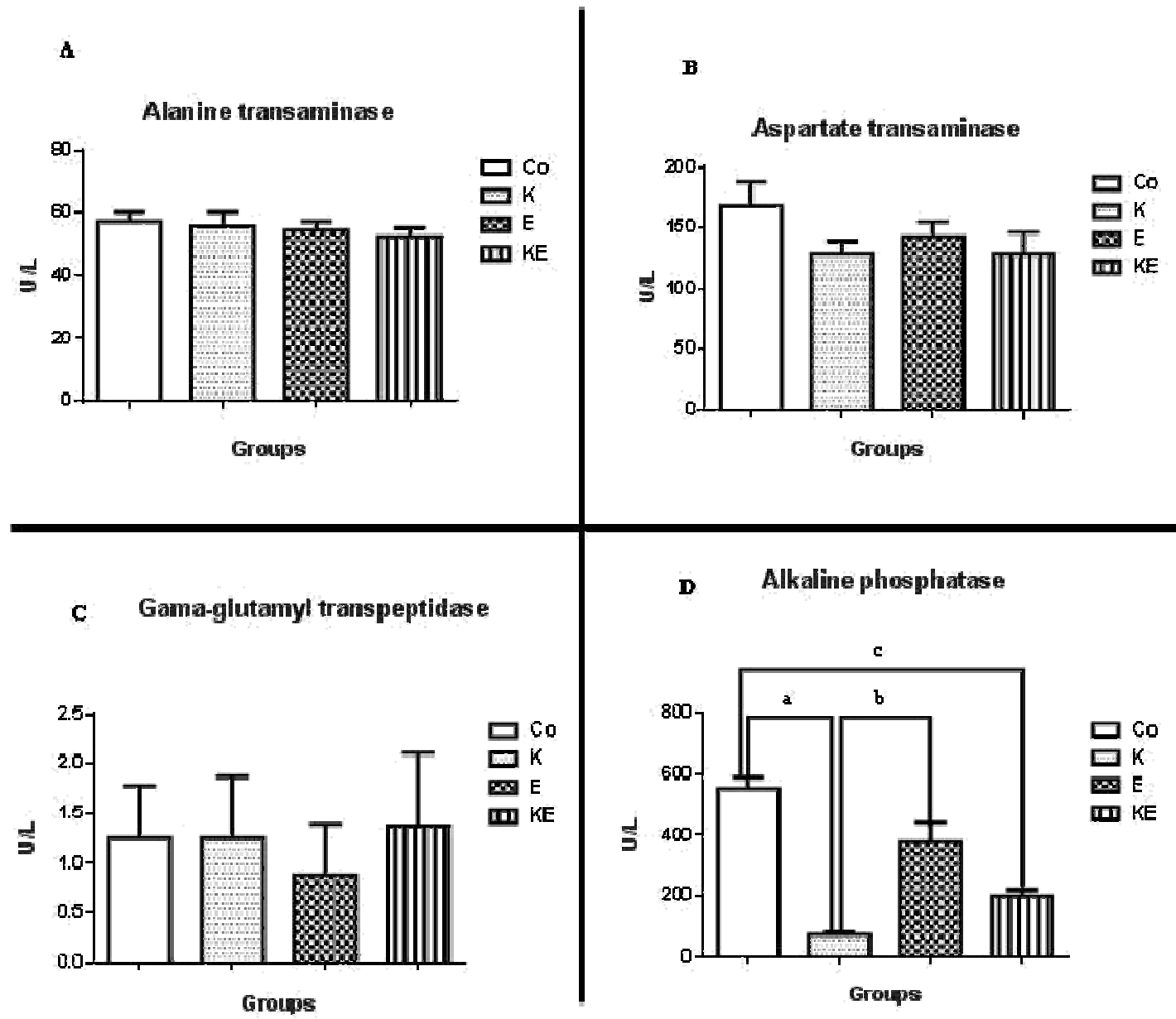

Fig. 1: Hepatic parameters of rats treated or not (Control-Co) with ketamine (K), ethanol (E) or ketamine+ethanol (KE) during 28 d. (A) Alanine transaminase; (B) aspartate transaminase, (C) gama-glutamyl transpeptidase and (D) alkaline phosphatase concentrations. Serum alkaline phosphatase concentrations were found reduced in both ketamine-treated groups (P<0.0001 K vs. Co, $\mathrm{P}<0.01 \mathrm{~K}$ vs. $\mathrm{E}$ and $\mathbf{P}<0.05$ KE vs. Co; Dunn test). In all cases $n=8$ animals/group. Data are expressed as mean \pm SEM 
A

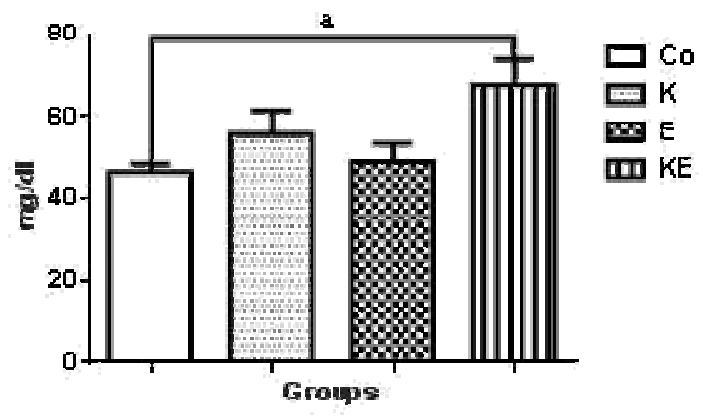

$\mathbf{B}$

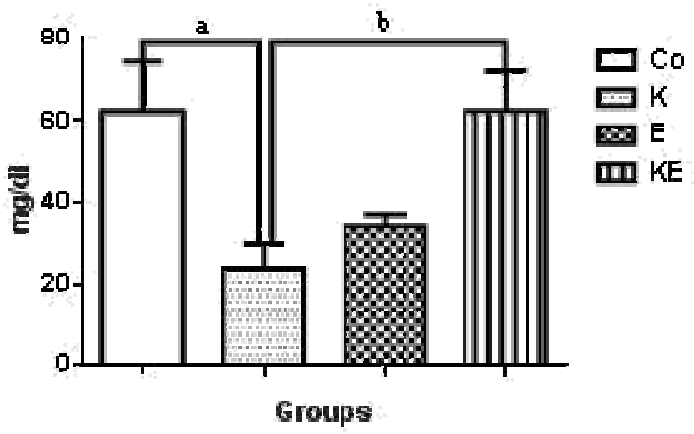

c High-density lipoproteins

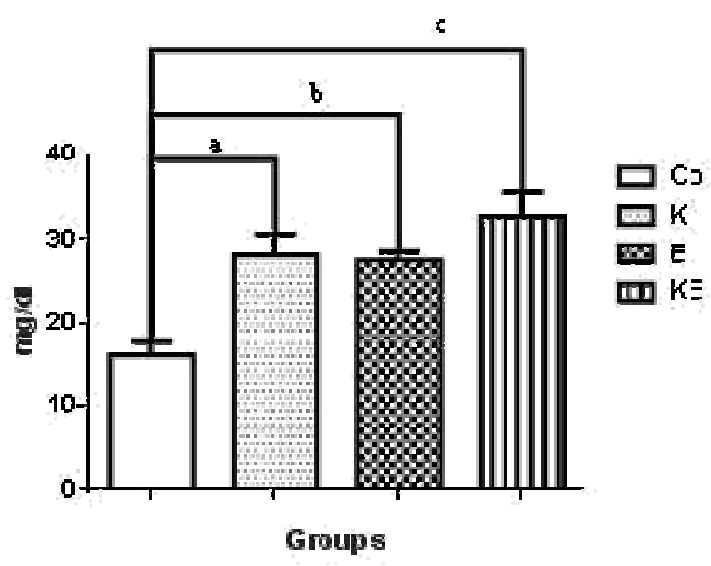

Fig. 2: Lipid profile of rats treated or not (Control-Co) with ketamine (K), ethanol (E) or ketamine+ethanol (KE) during $28 \mathrm{~d}$. (A) Cholesterol levels: enhanced levels were observed in KE group compared with Co group ( $\mathrm{P}<0.05 \mathrm{KE}$ vs. Co; post-test Tukey). (B) Triglycerides levels: Rats from $\mathrm{K}$ group showed reduced triglycerides levels when compared with rats from both KE and Co groups $(\mathrm{P}<0.05 \mathrm{~K}$ vs. Co and $\mathrm{P}<0.05 \mathrm{~K}$ vs. KE; post-test Dunn). (C) High-density lipoprotein levels (HDL): All treated groups showed enhanced levels of HDL compared with control group ( $\mathrm{P}<0.01 \mathrm{~K}$ vs $\mathrm{Co}, \mathrm{P}<0.01 \mathrm{E}$ vs $\mathrm{Co}, \mathrm{P}<0.0001 \mathrm{KE}$ vs Co; post-test Tukey). In all cases $\mathrm{n}=8$ animals/group. Data are expressed as mean \pm SEM

Regarding renal function, treatment with ketamine did not reveal any nephrotoxic effects; however, when ethanol was associated, it promoted a statistical enhancement on urea and creatinine levels, when compared with K alone (fig. 3A and B, respectively).
$\boldsymbol{A}$

Urea

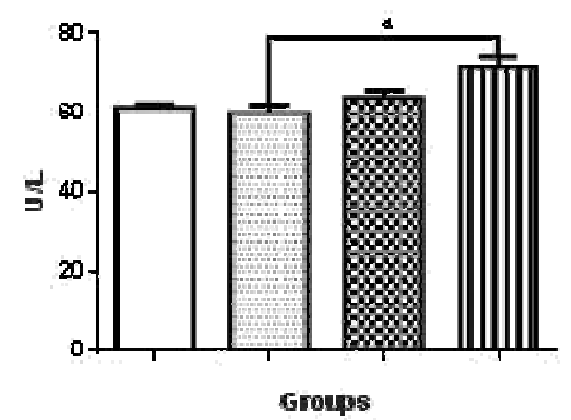

B

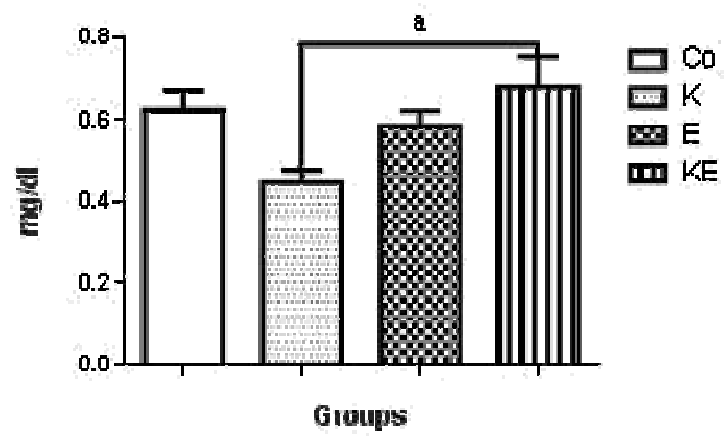

Fig. 3: Renal function of rats treated or not (Control-Co) with ketamine (K), ethanol (E) or ketamine+ethanol (KE) during $28 \mathrm{~d}$. (A) Urea levels. Urea levels were higher in the rats from the KE group compared with the rats from $K$ group ( $P<0.05 \mathrm{KE} v \mathrm{~K}$; post-test Tukey). (B) Creatinine levels. Creatinine levels were higher in the rats from the KE group compared with the rats from K group (P<0.05 KE vs K; posttest Tukey). In all cases $n=8$ animals/group. Data are expressed as mean \pm SEM 


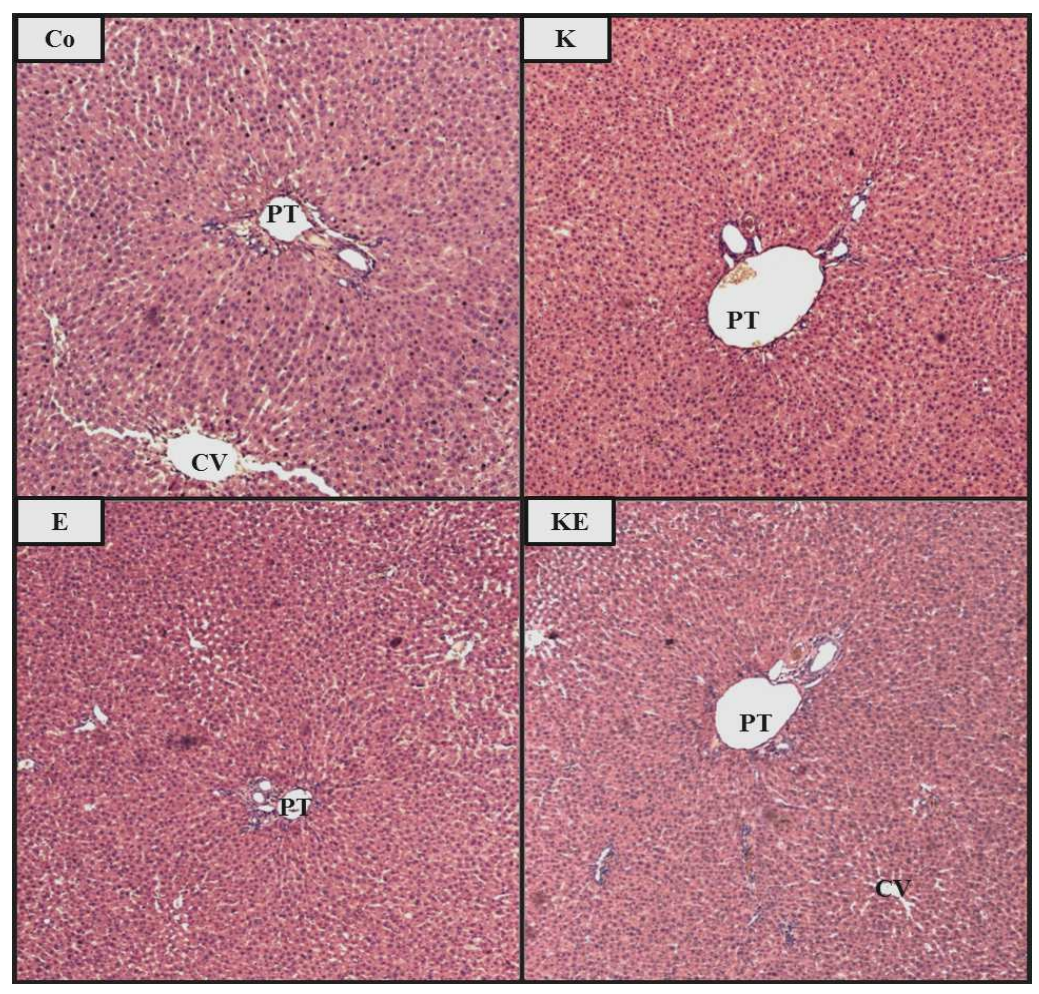

Fig. 4: Histopathological evaluation of liver (4x) of rats treated or not (Control-Co) with $15 \mathrm{mg} / \mathrm{kg}$ of ketamine intraperitoneally (IP) (K), 1 $\mathrm{ml}$ of ethanol $10 \%$ (gavage) (E) or ketamine $(15 \mathrm{mg} / \mathrm{kg}$, IP) followed by $1 \mathrm{ml}$ of ethanol $10 \%$ (gavage) (KE) during $28 \mathrm{~d}$. After the last day of treatment, organ sections were sliced, fixed, and stained with hematoxylin and eosin, as described in methods section. Livers appeared normal in all cases ( $n=8$ animals/group). $\mathrm{CV}=$ central vein; $\mathrm{PT}=$ portal tract

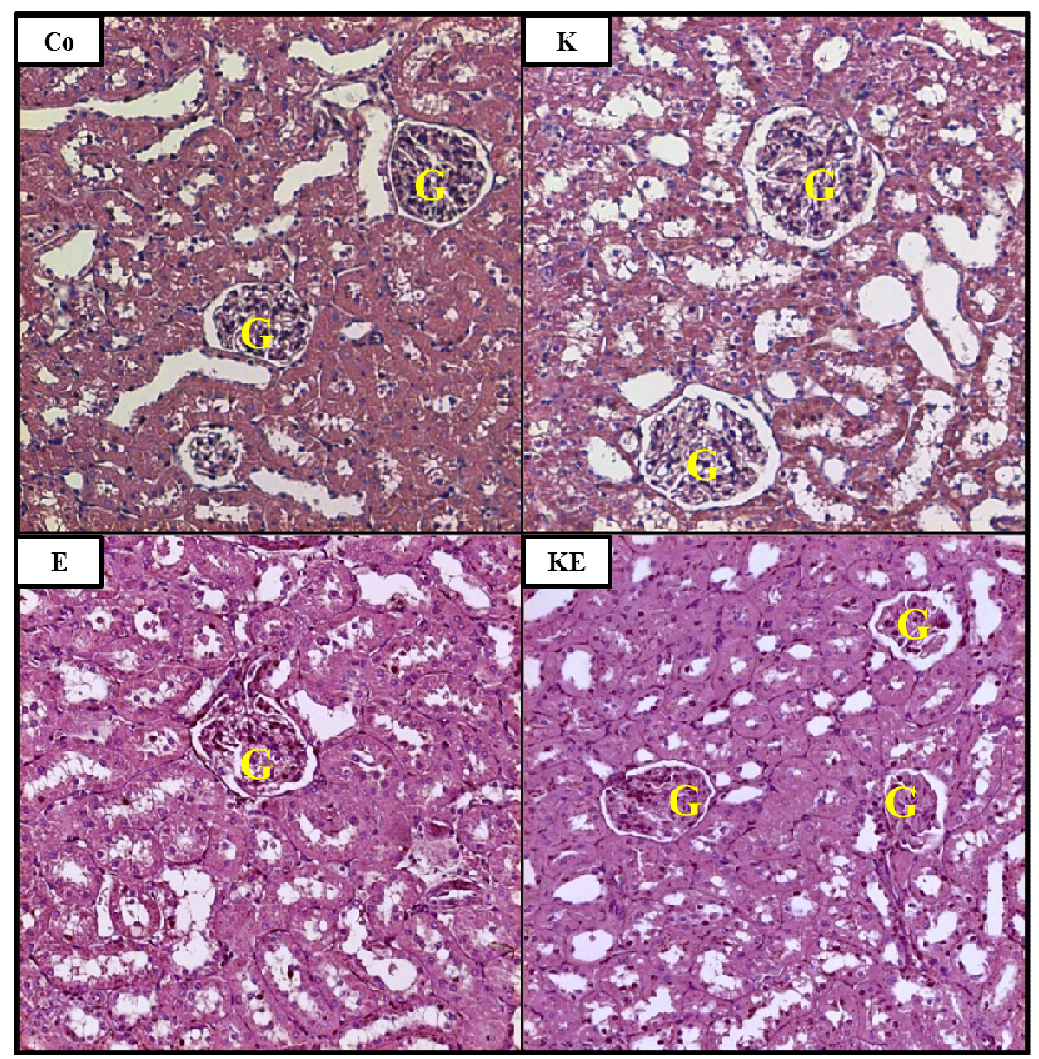

Fig. 5: Histopathological evaluation of kidney (10x) of rats treated or not (Control-Co) with $15 \mathrm{mg} / \mathrm{kg}$ of ketamine intraperitoneally (IP) (K), $1 \mathrm{ml}$ of ethanol 10\% (gavage) (E) or ketamine (15 mg/kg, IP) followed by $1 \mathrm{ml}$ of ethanol 10\% (gavage) (KE) during $28 \mathrm{~d}$. After the last day of treatment, organ sections were sliced, fixed, and stained with hematoxylin and eosin, as described in methods section. Kidneys appeared normal in all cases ( $\mathrm{n}=\mathbf{8}$ animals/group). $\mathrm{G}=$ glomerulus 


\section{Histopathological evaluations}

No histopathological alterations were observed in liver (fig. 4) or kidney (fig. 5), nor in any other organ analyzed (heart, thymus, spleen, Peyer's patches, mesenteric lymph nodes, adrenal glands and bladder).

\section{DISCUSSION}

"Polydrug" abuse is a current social phenomenon of public health concern [36], since the consumption of associated chemical substances can result not only in significant adverse effects [37, 38], but also culminate into the development of addiction processes [39-40].

Ethanol use as a licit drug $[10,41]$ is generally made in combination with a heterogeneous group of illegal chemical substances known as "club drugs", which are in constant renewal [42]. Ketamine, a prominent drug among these substances, was originally synthesized as an anaesthetic; however, because of its potential hallucinogenic effects, it has been used for recreational and illicit purposes $[10,41,42]$.

Considering the central [43] and immunomodulatory [31, 44] effects triggered by the isolated use of ketamine or ethanol, the combined use of these drugs can elicit additive, synergistic or even potentiated adverse effects on target organs [43].

Although several studies were conducted to determine the possible effects caused by the isolated use of ketamine and ethanol, scientific reports conducted to determine the effects of the combined use of both are rare. Thus, in the present study, we established an exposure scenario to both drugs, isolated or in combination, similar to what happens in clubs and/or parties.

In order to standardize worldwide protocols to evaluate the immunotoxicity of a chemical substance, the period of 28 consecutive days of treatment was chosen. In addition, to avoid the possible influence of female hormones, known to have immunomodulatory activity, such as estrogen $[45,46]$, we decided to use only male rats in our studies.

Moreover, when in vivo studies are conducted to assess the toxic effects on the immune system, it is important to verify if the doses employed are not capable of causing exacerbated toxicity and/or clinical signs in the animals tested [47], since secondary health disorders, such as fever $[48,49]$ or stress [50], can interfere in the immunological parameters evaluation. In that respect, the most significant toxicity signs observed in animal models are related to anorexia and weight loss [51].

The chosen concentration of ketamine to be used in our studies was based on previous works from different researchers [32-34] which aimed not to evaluate the toxicity, but the antidepressant potential of ketamine on different models of chronic stress in rats. In these studies, a dose of $15 \mathrm{mg} / \mathrm{kg}$ was able to promote biological effects, re-establishing several altered parameters, such as return of food intake, normalization of the circulating levels of corticosterone and adrenocorticotropic hormones, and reduction on proinflammatory cytokines serum levels, commonly elevated in depressed patients, evidencing, thus, the immunomodulatory potential of this dose.

In order to determine the ethanol dose to be used, a search in the literature showed different studies employing a variety of doses and models with different purposes, indicating the absence of treatment standardization in the attempt to mimic the drug consumption by its users. Thus, there are suggestions of ethanol administration in the drinking water [52-54], which in our opinion, can be stressful to the animal, since there is no other option of water intake, added to the uncertainty of the dose ingested. There are reports of parenteral administration $[55,56]$, which again is beyond the scope of this work. Finally, studies with administration by gavage $[57,58]$ appeared in our view to be the most suitable approach for our studies since it is the way that people usually use it.

Wai et al., [35] based the ethanol dose to be used in their studies on the usual consumption of wine drinkers (alcohol content $\approx 12 \%$ ), calculating a wine intake of $500 \mathrm{ml}$ per day by an adult of $50 \mathrm{~kg}$, resulting in mice (body weight $\approx 30 \mathrm{~g}$ ) in a dose of $0.5 \mathrm{ml}$ of a $10 \%$ solution of ethanol.

Knowing that club or rave-goers usually consume whiskey and energetic drinks to keep themselves "high", we decided to extrapolate on the dose employed by this researcher, considering the alcoholic content of the distillate, which varies from 40 to $60 \%$, and a volume of $40 \mathrm{ml}$ per serving, to a person with $60 \mathrm{~kg}$ of body weight [59]. Thus, considering the average value of the whiskey alcoholic content as $50 \%$, one serving of this drink $(40 \mathrm{ml})$ would be equivalent to the consumption of $0.27 \mathrm{~g} / \mathrm{kg}$ of ethanol. Accordingly, a dose of $1 \mathrm{ml}$ of a $10 \%$ ethanol solution, to rats with approximately $250 \mathrm{~g}$, amounts to $0.32 \mathrm{~g} / \mathrm{kg}$ of ethanol, an approximate value to that supposedly ingested by users.

A fact that draws the attention in the different studies conducted to evaluate ethanol and ketamine associated effects, is the absence of evaluation of food intake and body weight gain of the animals, important parameters to be considered for immunotoxic effects determination, as evaluated in this study. In fact, it is known that nutritional changes may result in related immune parameters alterations [60], for instance, thymus relative weight [61, 62], increased chronic inflammation susceptibility and recurrent infections [63].

The doses used in the present study, whether in combination or not, were unable to promote changes in water consumption, food intake, or body weight gain. In fact, Fataccioli et al., [64] in a study conducted in rats treated only with ethanol $10 \%$ on drinking water for $28 \mathrm{~d}$, did not observe any changes in these parameters. In the study of Rofael et al., [65] which evaluated the effects of orally administered ketamine in rats $(100 \mathrm{mg} / \mathrm{kg})$, associated or not with cocaine, ketamine alone did not promote changes in these parameters, corroborating our results. It is known that xylazine and ketamine association can promote anorexic effects in animals subjected to this anesthetic protocol $[66,67]$; however, it is worth remembering that xylazine can act on a class of $\alpha$-adrenergic receptors, including $\alpha 1$-adrenergic, related to the "feeding center" [68], while the central action of ketamine is mainly on NMDA receptors activity [69], which would justify the nonobservance of anorexic and body weight gain effects on the animals.

Ethanol is a caloric source and its consumption has been related to body weight gain and obesity in humans [70]. On the other hand, substantial amounts of its chronic consumption can lead to weight loss due to a carbohydrate isocaloric substitution by the ethanol [71]. However, the dose here employed presented an average of 97 calories/day, an insufficient value to promote effects on food intake and body weight gain.

Although some studies reported the effects of ethanol or ketamine on immune parameters, no data were found in the literature relating the possible immunotoxic effects resulting from the combination of these substances. Studies with rodents exposed to ketamine are usually associated with immunological challenges by infectious agents, showing reduced release of pro-inflammatory cytokines such as TNF- $\alpha$ [44], as well as in vitro inhibitory effects in nitric oxide (NO) synthesis by macrophages, evidencing an immunomodulatory effect on the resulting inflammatory response [72]. Studies with ethanol also showed its immunosuppressive potential, characterized by suppression of cytokines secretion and reduction of $\mathrm{B}$ and $\mathrm{T}$ lymphocytes population on lymphoid organs $[73,74]$.

Despite the immunomodulatory potential of ethanol or ketamine previously observed in laboratory animals, it is important to emphasize that the protocols employed by these researchers differ in several aspects, such as animal species, doses, administration routes, and experimental periods, including in vitro studies [72]. In none of these studies, animals were exposed to ketamine for a period of over $6 \mathrm{~h}[22,75]$. Ethanol doses varied up to $35 \%$ in drinking water, and the experimental period, up to $7 \mathrm{~d}$ [73].

Furthermore, it is known that the thymus is a lymphoid organ very sensitive to stress and toxic effects of substances [76]. Its relative weight, in conjunction with alterations in peripheral cellularity of white cells, constitutes important endpoints for testing the 
immunotoxic potential of chemicals by regulatory toxicity agencies, such as OECD (Organisation for Economic Co-operation and Development) and FDA (Food and Drug Administration). Thus, considering the results herein obtained, with the dosages and the administration period of $28 \mathrm{~d}$, it is not possible to conclude that ketamine and/or ethanol elicit immunotoxic effects, either alone or in combination.

It is known that ethanol exerts deleterious effects on the hepatocytes [77] since products originated from its biotransformation, involving the enzymes alcohol dehydrogenase and aldehyde dehydrogenase, can induce liver synthesis of collagen and hepatic fibrosis. The enzyme alcohol dehydrogenase generates $\mathrm{NADH}$, which can compromise the redox activity of cells and also contribute to changes in the metabolism of lipids [78], carbohydrates, proteins, and hepatic purines; and also generate acetaldehyde, causing glutathione depletion and consequent lipid peroxidation of the hepatocytes. Even more, the oxidation process by a specific system of cytochrome (CYP) P450 (P450IIE1) can also influence on the hepatotoxicity promoted by the chronic ingestion of ethanol [79-81].

Ketamine is biotransformed by several CYP system isoforms, which varies from species to species [82]. There are no reports about the possible hepatotoxic effect thereof, except in cases of high doses used for acute treatment of human patients with chronic pain, by infusion [83]. In fact, the results obtained here with the use of ketamine did not reveal any toxic effects of this anaesthetic. Moreover, despite the known toxicity of ethanol, it is possible to suggest that the dose and period of treatment used here, which also did not promote immunotoxicity, was not sufficient in terms of concentrations and exposure time, to cause any hepatotoxic effects in the animals.

Even though treatments did not elicit toxic or immunnotoxic effects, some biochemical changes were observed. ALP levels were decreased in both groups of animals treated with ketamine, although the same was not observed in animals exposed only to ethanol when compared with those of the control group. It is noteworthy that, despite the serum ALP specificity, which results from the sum of four isoenzymes activities from liver, kidney, bone, and intestines [84, 85], there were no indications of adverse effects in the histopathology of these organs in any treated animals. In fact, Bennett et al., [86] in monkeys exposed to ketamine, and González Gil et al., [87] in rabbits also exposed to this anesthetic, showed a statistically significant decrease in ALP levels after an acute treatment with ketamine. It is known that the ALP reduction may be due to vitamin B6 [88] and folic acid deprivation, or even due to less vitamin $\mathrm{E}$ absorption [89]. However, as previously described, our animals did not show any reduction in food intake that could lead to this decrease in serum ALP, thus, at this time, it is not possible to suggest any hypothesis about this phenomenon. Even more, the researchers that found similar results to these evidenced by us in different species of animals also did not infer any theory to this fact.

Regarding the animals lipid profile, an increase in the serum cholesterol levels from those belonging to KE group was observed, when compared with the Co group. In relation to serum levels of triglycerides, only animals of $\mathrm{K}$ group showed a statistically significant reduction in this parameter, compared with the animals of Co and KE groups. Furthermore, the animals of all experimental groups (K, E and KE) exhibited an increase in the serum HDL levels when compared with the animals of Co group.

It is known that chronic ethanol consumption can interfere with the liver lipid metabolism [90], being common the occurrence of high HDL $[91,92]$ and cholesterol $[93,94]$ levels. Furthermore, ketamine administration generally promotes an increase in serum cholesterol levels $[95,96]$ and changes in serum triglyceride levels [97, 98]. Studies conducted in different species of monkeys exposed to ketamine promoted both cholesterol and triglycerides increase in Macaca fascicularis [99], or the opposite effect, in Macaca radiata [100]. Thus, it is possible to suggest that the ketamine and/or ethanol treatment can promote synergistic or even antagonistic effects in the serum lipid markers.
It is known that the chronic recreational use of ketamine in humans can promote hemorrhagic cystitis, associated with chronic inflammation and urothelial ulceration [101], although the toxic mechanism of action involved in this process is still not fully elucidated. Our histopathological and urinalysis results were not able to show any significant alterations that could result in bladder injury, suggesting that the dose or exposure period employed were not sufficient to promote such effects.

On the other hand, the results for renal function showed that the treatment with ketamine, in combination with ethanol, increased creatinine levels when compared with the treatment with ketamine alone. In fact, a study conducted by Gvozdenovic et al., [102] in dogs exposed to ketamine and ethanol $12 \%$ in drinking water for $30 \mathrm{~d}$, showed that creatinine levels were also elevated in these animals, however, no effect was observed in urea levels, which did not characterize renal injury. In fact, ketamine is the anaesthetic drug of choice to be used in surgery of patients with some risk of kidney disease, as it does not promote any harmful effects in the kidneys [103]. In the case of ethanol, studies report that its chronic use can significantly increase urea and creatinine serum levels, as was observed by Das et al., [104] in rats exposed to ethanol (1.6 $\mathrm{g} / \mathrm{kg} / \mathrm{BW} /$ day) for $12 \mathrm{w}$.

\section{CONCLUSION}

In conclusion, even though the present experimental conditions of ketamine and ethanol administration did not elicit changes on immune organs of rats treated for $28 \mathrm{~d}$, changes on serum biochemistry of ALP levels, lipid profile alteration, and renal function were observed. Considering this, there is no doubt of the necessity to perform further experiments in order to investigate and elucidate such effects, since different and not always consistent results were observed by other authors, using either different doses, routes of administration, animal models, or periods of experimentation from those used here. Thus, the future goal of our research group is to delineate other experimental trials targeting these effects, in order to better understand the possible toxic mechanism of action of each drug and to establish if the association of both may result in a synergistic/antagonistic mode of action to promote intoxication.

\section{AUTHOR CONTRIBUTION}

Patrícia Franciscone Mendes: performed all animal experimentation and laboratorial analyses, also executed the statistical analyses, results in interpretation and paper writing.

Karin Argenti Simon: development of the experimental design, selection of drug doses, period and route of administration, performance in some experimental procedures, discussion of the results and paper writing.

Isis Machado Hueza: first author adviser's, development of the experimental design, selection of drug doses, period and route of administration, performance in some experimental procedures, discussion of the results and paper writing.

\section{CONFLICT OF INTERESTS}

The authors declare that there is no conflict of interest

\section{FUNDING}

This work was supported by the Conselho Nacional de Desenvolvimento Científico e Tecnológico, CNPq, Brazil [grant number 140019/2015-4] that provided financial support for the conduction of this research.

\section{REFERENCES}

1. Tavares BF, Beria JU, Lima M. Prevalência do uso de drogas e desempenho escolar entre adolescentes. Rev Saude Publica 2001;35:150-8.

2. Macht DI. The history of opium and some of its preparation and alkaloids. JAMA 1915;64:477-61.

3. Booth M. Opium-a history, New York: St Martin's Griffin; 1998. 
4. Orth APS, More CLO. Funcionamento de famílias com membros dependentes de substâncias psicoativas. Psicologia Argumento 2008;26:293-303.

5. Focchi GRA. Dependência de drogas: uma abordagem para leigos. Psyquiatry Online Brazil 2004;9:1-15.

6. Silva FCC, Dantas RT, Cito MCO, Silva MIG, Vasconcelos SMM, Fonteles MMF, et al. Ketamina, da anestesia ao uso abusivo: artigo de revisão. Rev Neurosci 2010;18:227-37.

7. Suvarna Y, Shivamurthy MC. Therapeutic use of dependence causing agents: the past and the present. J Crit Rev 2016;3:44-7.

8. WHO. Ketamine: update review report. Geneva, Switzerland: World Health Organization; 2015.

9. Yen CF, Hsu SY, Cheng CP. Polysubstance use and its correlates in adolescent ecstasy users in Taiwan. Addict Behav 2007;32:2286-91.

10. Kenna GA, Lewis DC. Risk factors for alcohol and other drug use by healthcare professionals. Subst Abuse Treat Prev Policy 2008;3:1-8.

11. Food and Drug Administration-FDA. Ketamine abuse. FDA Drug Bull 1979;9:24.

12. Jansen KL. A review of the nonmedical use of ketamine: use, users and consequences. J Psychoactive Drugs 2000;32:419-33.

13. UNODC. World drug report. Vienna: United Nations Publications: United Nations office on Drugs and Crime; 38. p. 2016

14. Advisory Council on the Misuse of Drugs-ACMD. A consultation on proposals to reschedule ketamine under the Misuse of Drugs Regulations; 2014. p. 1-15.

15. DEA. Schedules of Controlled Substances: Placement of Ketamine into Schedule III. United States: U. S. Department of Justice-Drug Enforcement Administration; 1999.

16. Anis NA, Berry SC, Burton NR, Lodge D. The dissociative anaesthetics, ketamine and phencyclidine, selectively reduce excitation of central mammalian neurones by $\mathrm{N}$-methylaspartate. Br J Pharmacol 1983;79:565-75.

17. Berman RM, Cappiello A, Anand A, Oren DA, Heninger GR, Charney DS, et al. Antidepressant effects of ketamine in depressed patients. Biol Psychiatry 2000;47:351-4.

18. Zarate CAJr, Singh JB, Carlson PJ, Brutsche NE, Ameli R, Luckenbaugh DA, et al. A randomized trial of an N-Methyl-DAspartate antagonist in treatment-resistant major depression. Arch Gen Psychiatry 2006;63:856-64.

19. Krystal JH, Karper LP, Seibyl JP, Freeman GK, Delaney R, Bremner JD, et al. Subanaesthetic effects of the noncompetitive NMDA antagonist ketamine in humans. Arch Gen Psychiatry 1994;51:199-214.

20. Abanades S, Peiro AM, Farre M. Club drugs: old medicines as new party drugs. Med Clin 2004;123:305-11.

21. Wolff K, Winstock AR. Ketamine from medicine to misuse. CNS Drugs 2006;20:199-18.

22. Sun J, Li F, Cheng J, Xu J. Effect of ketamine on NF-kappa B activity and TNF-alpha production in endotoxin-treated rats. Ann Clin Lab Sci 2004;34:181-6.

23. Beilin B, Rusabrov Y, Shapira Y, Roytblat L, Greemberg L, Yardeni IZ, et al. Low-dose ketamine affects immune responses in humans during the early post-operative period. Br J Anaesth 2007;99:522-7.

24. Roussabrov E, Davies JM, Bessler H, Davies JM, Shapira Y. Effect of ketamine on inflammatory and immune responses after short-duration surgery in obese patients. Open Anesthesiol J 2008;2:40-5.

25. Zahler S, Heindl B, Becker BF. Ketamine does not inhibit inflammatory responses of cultured human endothelial cells but reduces chemotactic activation of neutrophils. Acta Anaesthesiol Scand 1999;43:1011-6.

26. Weigand $M$, Schmidt $H$, Zhao Q, Plaschke K, Martin E, Bardenheuer HJ. Ketamine modulates the stimulated adhesion molecule expression on human neutrophils in vitro. Anesth Analg 2000;90:206-12.

27. PDF. Alcohol and Drug Problem Overview. New York: Partnership for a Drug-Free.org; 2010. p. 5.
28. UNODC. World Drug Report 2012. New York: United Nations Publications: United Nations office on Drugs and Crime; 2012. p. 112.

29. Davies M. The role of GABAA receptors in mediating the effects of alcohol in the central nervous system. J Psychiatry Neurosci 2003;28:263-74.

30. Schuckit MA. Alcohol-use disorders. Lancet 2009;373:492-501.

31. Molina PE, Happel KI, Zhang P, Kolls JK, Nelson S. Focus on: alcohol and immune system. Alcohol Res Health 2010;33:97108.

32. Garcia LS, Comim CM, Valvassori SS, Reus GZ, Stertz L, Kapczinski F, et al. Ketamine treatment reverses behavioral and physiological alterations induced by chronic mild stress in rats. Prog Neuropsychopharmacol Biol Psychiatry 2009;33:450-5.

33. Rezin GT, Gonçalvez CL, Daufenbach JF, Fraga DB, Santos PM, Ferreira GK, et al. Acute administration of ketamine reverses the inhibition of mitochondrial respiratory chain induced by chronic mild stress. Brain Res Bull 2009;79:418-21.

34. Réus GZ, Nacif MP, Abelaira HM, Tomaz DB, dos Santos MA, Carlessi AS, et al. Ketamine ameliorates depressive-like behaviors and immune alterations in adult rats following maternal deprivation. Neurosci Lett 2015;584:83-7.

35. Wai MSM, Chan WM, Zhang AQ, Wu Y, Yew DT. Long-term ketamine and ketamine plus alcohol treatments produced damages in liver and kidney. Hum Exp Toxicol 2012;31:877-86.

36. Engleman EA, Rodd ZA, Bell RL, Murphy JM. The role of 5-HT3 receptors in drug abuse and as a target for pharmacotherapy. CNS Neurol Disord Drug Targets 2008;7:454-67.

37. Coffin P, Galea S, Ahern J, Leon AC, Vlahov D, Tardiff K. Opiates, cocaine and alcohol combinations in accidental drug overdose deaths in New York City. Addiction 2003;98:739-47.

38. Coffin P, Sherman S, Curtis M. Underestimated and overlooked: a global overview of drug overdose and overdose prevention. London: International Harm Reduction Association; 2010.

39. Peters A, Davies T, Richardson A. Multi-site samples of injecting drug users in Edinburgh: prevalence and correlates of risky injecting practices. Addiction 1998;92:253-67.

40. EMCDDA. The state of drugs problem in Europe. Luxembourg: Publications Office of the European Union: European Monitoring Centre for Drugs and Drug Addiction; 2012.

41. ACMD. Ketamine: a review of use and harm. London, England: Advisory Council on the Misuse of Drugs; 2013. p. 48.

42. WHO. Expert Committee on Drug Dependence. Geneva, Switzerland: World Health Organization; 2006.

43. Chan WM, Xu J, Fan M, Jiang Y, Tsui TY, Wai MS, et al. Downregulation in the human and mice cerebella after ketamine versus ketamine plus ethanol treatment. Malar Res Treat 2011;75:258-64.

44. De Kock M, Loix S, Lavand'homme P. Ketamine and peripheral inflammation. CNS Neurol Ther 2013;19:403-10.

45. Lang TJ. Estrogen as an immunomodulator. Clin Immunol 2004:113:224-30.

46. Walker SE. Estrogen and autoimmune disease. Clin Rev Allergy Immunol 2011;40:60-5.

47. FDA. General Toxicology Studies. Rockville, Maryland: Food and Drug Administration; 2009;4:42-67.

48. Heron I, Berg K. The actions of interferon are potentiated at elevated temperature. Nature 1978;274:508-10.

49. Roberts NJJr. Impact of temperature elevation on immunologic defenses. Rev Infect Dis 1991;13:462-72.

50. Idova $G$, Cheido $M$, Devoino L. Modulation of the immune response by changing neuromediator systems activity under stress. Int J Immunopharmacol 1997;19:535-40.

51. Stevens KR, Gallo MA. Practical considerations in the conduct of chronic toxicity studies. Principles and methods of toxicology, New York: Raven Press; 1989. p. 929.

52. Bosma A, Brouwer A, Seifert WF, Knook DL. Synergism between ethanol and carbon tetrachloride in the generation of liver fibrosis. J Pathol 1988;156:15-21.

53. Kuzmin A, Liljequist S, Meis J, Chefer V, Shippenberg T, Bakalkin G. Repeated moderate-dose ethanol bouts impair cognitive function in Wistar rats. Addict Biol 2012;17:132-40. 
54. Baptista RFF, Taipeiro EF, Queiroz RHC, Chies AB, Cordellini S. Estresse isolado ou associado ao etanol libera prostanóides em aorta de ratos via $\alpha 2$-adrenoceptores. Arq Bras Cardiol 2012; 102:211-8.

55. Nelson S, Bagby G, Summer WR. Alcohol suppresses lipopolysaccharide-induced tumor necrosis factor activity in serum and lung. Life Sci 1989;44:673-76.

56. Greenberg S, Zhao X, Hua L, Wang JF, Nelson S, Ouyang J. Ethanol inhibits lung clearance of Pseudomonas aeruginosa by a neutrophil and nitric oxide-dependent mechanism in vivo. Alcohol Clin Exp Res 1999;23:735-44.

57. Jerrells TR, Marietta CA, Eckardt MJ, Majchrowicz E, Weight FF. Effects of ethanol administration on parameters of immunocompetence in rats. J Leukocyte Biol 1986;39:499-510.

58. Abadie-Guedes R, Guedes RCA, Bezerra RS. The impairing effect of acute ethanol on spreading depression is antagonized by astaxanthin in rats of 2 young-adult ages. Alcohol Clin Exp Res 2012;36:1563-7.

59. ANVISA. Agencia Nacional de Vigilancia Sanitaria; 2016. Available from: http://portal.anvisa.gov.br. [Last accessed on 01 Jul 2017].

60. Kale MA, Bindu SM, Khadkikar P. Role of antioxidants and nutrition in oxidative stress: a review. Int J Appl Pharm 2015;7:1-4.

61. Chandra RK. Protein-energy malnutrition and immunological responses. J Nutr 1992;122:597-600.

62. Prentice AM. The thymus: a barometer of malnutrition. Br J Nutr 1999;81:345-7.

63. Bourke CD, Berkley JA, Prendergast AJ. Immune dysfunction as a cause and consequence of malnutrition-review. Trends Immunol 2016;37:386-98.

64. Fataccioli V, Andraud E, Gentil M, French SW, Rouach H. Effects of chronic ethanol administration on rat liver proteasome activities: relationship with oxidative stress. Hepatology 1999;29:14-20.

65. Rofael HZ. Effect of ketamine pretreatment on cocainemediated hepatotoxicity in rats. Toxicol Lett 2004;152:213-22.

66. Warren RJ, Kirkpatrick RL, Gibson DF, Scanlon PF. Xylazine hydrochloride-induced anorexia in white-tailed deer. JWD 1984;20:66-8

67. Van Der Eems K, Brown RD. Effect of caffeine sodium benzoate, ketamine hydrochloride, and yohimbine hydrochloride on xylazine hydrochloride-induced anorexia in white-tailed deer. JWD 1986;22:403-6.

68. Docherty JR, McGrath JC. A comparison of pre and post junctional potencies of several alpha-adrenoceptor agonists in the cardiovascular system and anococcygeus muscle of the rat. Evidence for two types of post junctional alpha-adrenoceptor. Naunyn Schmiedebergs Arch Pharmacol 1980;312:107-16.

69. Harrison NL, Simmonds MA. Quantitative studies on some antagonists of $\mathrm{N}$-methyl $\mathrm{D}$-aspartate in slices of rat cerebral cortex. Br J Pharmacol 1985;84:381-91.

70. Suter PM. Is alcohol consumption a risk factor for weight gain and obesity? Crit Rev Clin Lab Sci 2005;42:197-227.

71. Lieber CS. Perspectives: do alcohol calories count? Am J Clin Nutr 1991a;54:976-82.

72. Kawasaki T, Ogata M, Kawasaki C, Ogata J, Inoue Y, Shigematsu A. Ketamine suppresses proinflammatory cytokine production in human whole blood in vitro. Anesth Analg 1999;89:665-9.

73. Starkenburg S, Munroe ME, Waltenbaugh C. Early alteration in leukocyte populations and Th1/Th2 function in ethanolconsuming mice. Alcohol Clin Exp Res 2001;25:1221-30.

74. Szabo G, Mandrekar P, Dolganiuc A, Catalano D, Kodys K. Reduced all reactive $\mathrm{T}$-cell activation after alcohol intake is due to impaired monocyte accessory cell function and correlates with elevated IL-10, IL-13, and decreased IFN gamma levels. Alcohol Clin Exp Res 2001;25:1766-72.

75. Taniguchi T, Shibatta K, Yamamoto K. Ketamine inhibits endotoxin-induced shock in rat. Anesthesiology 2001;95:928-32.

76. Pearse G. Normal structure, function and histology of the thymus. Toxicol Pathol 2006;34:504-14.

77. Singh G, Dhadwal N, Harikumar SL. Experimental models for hepatotoxicity. Asian J Pharm Clin Res 2015;8:70-4.
78. Verma N. Introduction to hyperlipidemia and its treatment: a review. Int J Curr Pharm Res 2017;9:6-14.

79. Lieber CS. Mechanism of ethanol induced hepatic injury. Pharmacol Ther 1990;46:1-41.

80. Lieber CS. Metabolism of ethanol and associated hepatotoxicity. Drug Alcohol Rev 1991b;10:175-202.

81. Boubekri N, Boukaabache R, Amrani A, Belfarhi L, Zama D, Boumaza 0, et al. Hepatoprotective effect of Genista quadriflora munby extract against ethanol induced toxicity. Asian J Pharm Clin Res 2014;7:226-9.

82. Mössner LD, Schmitz A, Theurillat R, Thormann W, Mevissen M. Inhibition of cytochrome P450 enzymes involved in ketamine metabolism by use of liver microsomes and specific cytochrome P450 enzymes from horses, dogs, and humans. Am J Vet Res 2011;72:1505-13.

83. Noppers IM, Niesters M, Aarts LP, Bauer MC, Drewes AM, Dahan A, et al. Drug-induced liver injury following a repeated course of ketamine treatment for chronic pain in CRPS type 1 patients: a report of 3 cases. Pain 2011;152:2173-8.

84. Madsen NB, Tuba J. On the source of the alkaline phosphatase in rat serum. J Biol Chem 1952;195:741-50.

85. Hoffmann WE, Everds N, Pignatello M, Solter PF. Automated and Semiautomated analysis of rat alkaline phosphatase isoenzymes. Toxicol Pathol 1994;22:633-8.

86. Bennett JS, Gosset KA, McCarthy MP, Simpson ED. Effects of ketamine hydrochloride on serum biochemical and hematologic variables in rhesus monkeys (Macaca mulatta). Vet Clin Pathol 1992;21:15-8.

87. González Gil A, Illera JC, Silván G, Illera M. Effects of the anaesthetic/tranquillizer treatments on selected plasma biochemical parameters in NZW rabbits. Lab Anim 2003;37:155-61.

88. Narisawa S, Wennberg C, Millán JL. Abnormal vitamin B6 metabolism in alkaline phosphatase knock-out mice causes multiple abnormalities, but not the impaired bone mineralization. J Pathol 2011;193:125-33.

89. Farrokhifar SH, Jafari RA, Majd NE, Tabatabaee SRF, Mayahi M. Effects of dietary vitamin $\mathrm{E}$ on mucosal maltase and alkaline phosphatase enzyme activities and on the amount of mucosal malonyl dialdehyde in broiler chickens. Vet Res Forum 2013;4:221-5.

90. Wang Z, Yao T, Song Z. Chronic alcohol consumption disrupted cholesterol homeostasis in rats: downregulation of low-density lipoprotein receptor and enhancement of cholesterol biosynthesis pathway in the liver. Alcohol Clin Exp Res 2010;34:471-8.

91. Feinman L, Lieber CS. Ethanol and lipid metabolism. Am J Clin Nutr 1999;70:791-2.

92. Rimm EB, Williams $\mathrm{P}$, Fosher $\mathrm{K}$, Crigui M, Stampfer MJ. Moderate alcohol intake and lower risk of coronary heart disease: meta-analysis of effects on lipids and haemostatic factors. Br Med J 1999;319:1523-8.

93. DeCarli LM, Lieber CS. Fatty liver in the rat after prolonged intake of ethanol with a nutritionally adequate new liquid diet. J Nutr 1967;91:331-6.

94. Lefevre AF, DeCarli LM, Lieber CS. Effect of ethanol on cholesterol and bile acid metabolism. J Lipid Res 1972; 13:48-55.

95. Van Der Merwe JN, Du Bruyn DB, Van Der Walt WH, Sly MR. Effects of certain anaesthetics on plasma metabolite concentrations in the baboon (Papio ursinus). J S Afr Vet Assoc 1987;58:125-9.

96. Rovirosa-Hernandez MJ, Garcia-Orduna F, Caba M, CanalesEspinosa D, Hermina-Lagunes J, Torres-Pelayo VR. Blood parameters are little affected by time of sampling after the application of ketamine in black howler monkeys (Alouatta pigra). J Med Primatol 2011;40:294-9.

97. Yoshida T, Suzuki K, Shimizu T, Cho F, Honjo S. The effects of ketamine anesthesia on hematological and serum biochemical values in female cynomolgus monkeys (Macaca fascicularis). Jikken Dobutsu 1986;35:455-61.

98. González Gil A, Silvan G, Illera M, Illera JC. The effects of anesthesia on the clinical chemistry of New Zealand White rabbits. Contemp Top Lab Anim Sci 2004;43:25-9. 
99. Kim CY, Lee HS, Han SC, Heo JD, Kwon MS, Ha CS, et al. Hematological and serum biochemical values in Cynomolgus monkeys anesthetized with ketamine hydrochloride. J Med Primatol 2005;34:96-100

100. Venkatesan R, Nagarajan P, Rajaretnam RS, Majumdar SS. Hematologic and serum biochemical values in aged female bonnet machaques (Macaca radiata) anesthetized with ketamine hydrochloride. J Am Assoc Lab Anim Sci 2006; 45:45-8.

101. Baker SC, Stahlschmidt J, Oxley J, Hinley J, Eardley I, Marsh F, et al. Nerve hyperplasia: a unique feature of ketamine cystitis. Acta Neuropathol Commun 2013;1:64.

102. Gvozdenovic LV, Popovic MR, Jakovljevic VS, Lukic V. Effect of fentanyl, ketamine and thalamonal on some biochemical parameters in ethanol-treated and untreated dogs. Hum Exp Toxicol 1993;12:279-83.

103. Rezende M, Mama K. Anesthesia for patients with renal disease. Clini Brief; 2015. p. 41-4.

104. Das SK, Varadhan S, Dhanya L, Mukherjee S, Vasudevan DM. Effects of chronic ethanol exposure on renal function tests and oxidative stress in kidney. Indian J Clin Biochem 2008:23:341-4.

\section{How to cite this article}

- $\quad$ Patricia Franciscone Mendes, Karin Argenti Simon, Isis Machado Hueza. Toxic and immunotoxic evaluation of ketamine and/or ethanol in rats during 28 D. Int J Pharm Pharm Sci 2017;9(9):205-214. 